of the negro languages between the Shari River on the east and the forests of West Africa, overlaid as these innumerable types of speech may be by other unrelated tongues, implanted at a later date in Equatorial Africa. We now know that the range of actual Semi-Bantu languages extends from the Lower and the Upper Gambia eastwards to the watershed of Lake Chad. Mr. Du Plessis lays stress on the ethnic importance of the A-zande, or Nyamnyam. Undoubtedly they will play a part in the future development of the western Bahr-al-Ghazal and the Mubangi-Wele basin as important as that of the Fula in Nigeria or the Mandingos of Senegambia.

Much information is given concerning the artistic aptitudes of various negro peoples, espe- has long been one of the primary aims of astronomy to execute this enumeration. Considerable difficulties of a practical nature have to be faced in the course of the work, however, and only now do they appear to have been so far overcome as to enable a consensus of opinion to be formed amongst astronomers regarding the main features of the results. Whether visual or photographic methods are used, it is anything but easy to determine star magnitudes according to an absolute scale of light-ratio, and to maintain a constant zero point for the scale in widely separated regions of the sky.

The photometric work done at the Harvard and Mount Wilson observatories has greatly facilitated this task, and at these institutions, moreover,

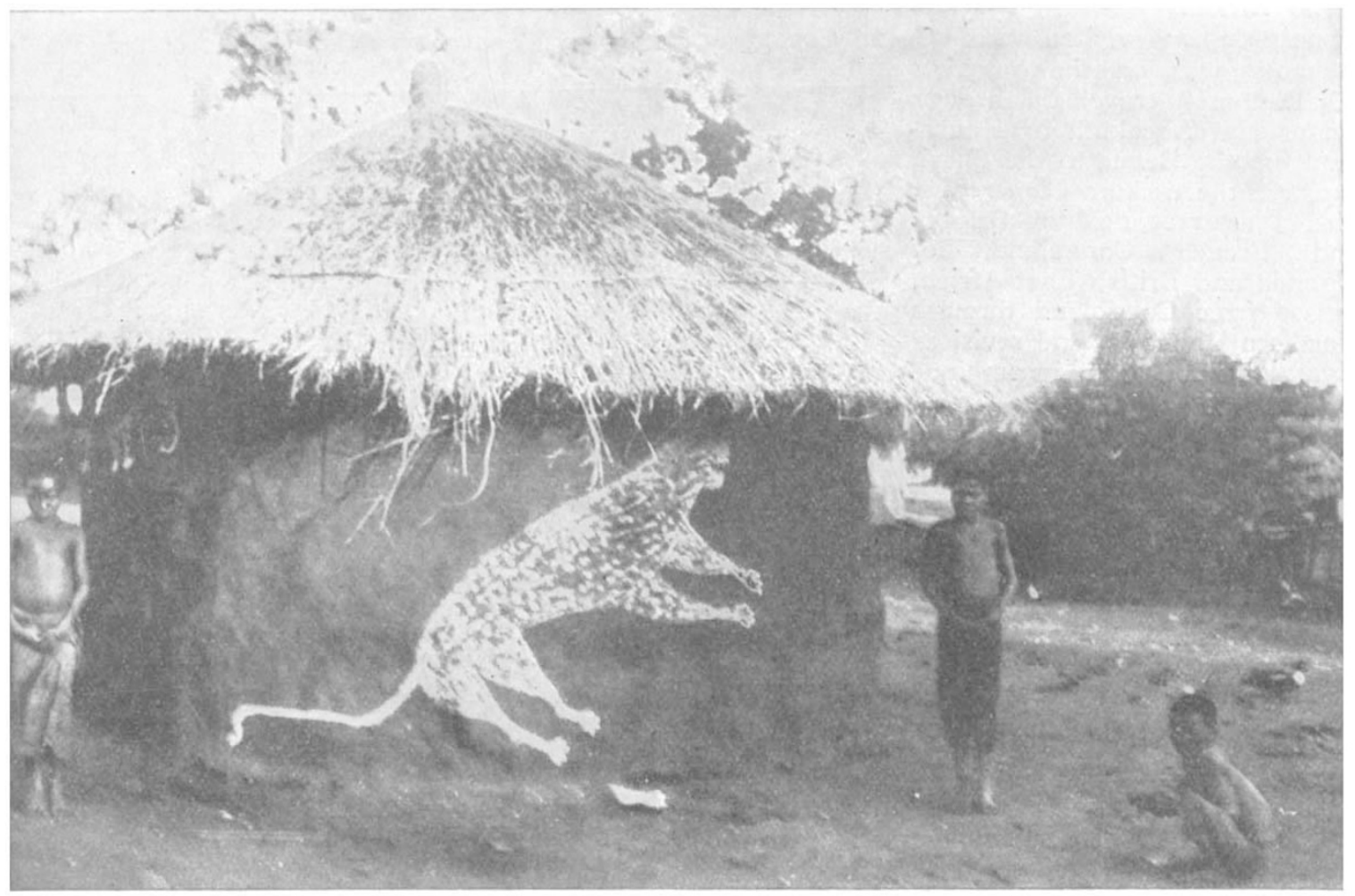

F1G. 2.-A specimen of native art (British Nyasaland). From "Thrice through the Dark Continent."

cially of the Nyamnyam, the Basonge (of central Congoland), and the A-nyanja of Nyasaland. A good deal of this desire to draw and paint and decorate is subsequent rather than prior to the establishment of European influence. Personally I believe that the negro may rise very high in the pictile arts, and that he has an inherent good taste and originality in design.

H. H. Johnston.

\section{THE NUMBER AND DISTRIBUTION OF THE STARS.}

A $N$ enumeration of the stars, classified accordA ing to their brightness and their position in the sky, must form a part of any general investigation into the nature of the stellar universe. It extensive schemes for the photographic survey of sample areas of the sky have recently been carried out. The Harvard plates have been measured, and a preliminary discussion of them made, at the Groningen Astronomical Laboratory; an account of this work, ${ }^{1}$ and a brief note ${ }^{2}$ upon that done at Mount Wilson, have lately appeared. In both cases the investigation has been extended to very faint stars (of magnitude 155 and $I 75$ respectively); these are so numerous that counts of small sample areas, and the formation of statistical averages, afford the only practical means of attack upon the problem. The areas dealt with were among those 1 Publications of the Astronomical Laboratory at Groningen. No. 27, "On the Number of Stars of Each Photographic Magnitude in Differen Galactir Iatitudes." By Dr. P. I. van Rhijn. (ig17.)

2 F. H. Seares, Proc. Nat. Acad. Sci., Washington, v 1. iii., p. 217. (r917.)

NO. 2503, VOL. IOO] 
selected by Prof. Kapteyn for his "Plan of Selected Areas" (1906), the number of regions for which data were available for preliminary discussion being sixty-five at Harvard and eightyeight at Mount Wilson. Dr, van Rhijn's discussion is much the more detailed, Prof. Seares dealing only with the numbers of stars down to the limiting magnitude on each plate. The two investigations agree, however, in indicating a progressive increase in the concentration of the stars towards the galactic plane, as we proceed from brighter to fainter stars. Comparing star densities $(a)$ in a belt of $20^{\circ}$ on either side of the galaxy, and $(b)$ in the caps of $50^{\circ}$ radius round the galactic poles, the ratio is found to be $2^{\circ} 5$ for stars brighter than $5^{\mathrm{m} * \mathrm{o}}$ or $6^{\mathrm{m}} \mathrm{o}, 55$ for stars brighter than $16^{\mathrm{m}} \mathrm{o}$ (Harvard), and about ro for those brighter than $\mathrm{I} 7^{\mathrm{m}}$. (Mount Wilson); magnitudes are here reckoned on the revised Harvard photographic scale.

These results differ to some extent from those arrived at by earlier investigators, among whom the more recent are Pickering (1903), Kapteyn (Igo8), and Chapman and Melotte (I9I4). The differences, however, can now, in the main, be accounted for. The counts on which the firstmentioned work was based were incomplete in the richer regions of the sky, and the galactic condensation thus appeared to increase but little for the fainter stars. Kapteyn's memoir, on the contrary, gave values of the condensation which are larger than those mentioned above, but which are brought into fair agreement with them when his magnitude scale is corrected to the absolute scale determined more recently. Chapman and Melotte's investigation, which was photographic (thirty plates), and in many respects similar to the new Harvard-Groningen study, gave too small a galactic concentration for the faint stars (i.e. $3^{\circ} \mathrm{I}$ at ${ }^{1} 6^{\mathrm{m} \cdot \mathrm{o}}$ ). Dr. van Rhijn points out that the method of reduction which they adopted was faulty, and would lead to too small a value; from a note in his memoir it appears that, after allowing for this error, Chapman and Melotte find that their data yield results in close accordance with his own.

It is of interest to note that Dr. van Rhijn's estimate of the total number of stars in the sky brighter than the 16 th magnitude is approximately thirty-three millions. Also, if the law of increase in number which is obeyed down to this limit is used to obtain, by extrapolation, an estimate of the total number of stars of all magnitudes, the result is found to be 3360 millions; of these stars about half will be brighter than magnitude $25^{\circ} 5$.

S. C.

\section{ALCOHOL FUEL AND ENGINES.}

THE special committee on "Alcohol Fuel and Engines" of the Australian Commonwealth Advisory Committee on Science and Industry has presented its first report. The need for such an investigation arises from the prospective shortage of supplies of mineral oils and the consequent high price of motor spirit.

NO. 2503 , VOI. IOO
There are three branches into which the inquiry divides, namely, the design and manufacture of the engine, the supply of the alcohol, and its denaturation. As the committee points out, there is no special difficulty with the engine; indeed, the use of alcohol, by permitting the compression ratio to be increased considerably, offers a prospect of some gain in thermal economy. Nor with a given engine need there be any loss of power, since the average calorific value per unit volume of a mixture of alcohol with the air necessary for its combustion is almost identical with the corresponding figure for petrol. Nevertheless, if alcohol be compared with petrol pound for pound, the latter has the advantage by some 50 per cent. A comparison gallon for gallon is more favourable to alcohol, but, whichever be adopted, alcohol needs to be at a lower unit price than petrol to be the more economical fuel.

Alcohol unfortunately suffers from the grave disadvantage that an engine will not" start up from the cold" with it, whereas its alternative rival, benzol, will easily enable this to be done on all but the very coldest days. Doubtless the possible use of benzol was outside the terms of the reference of this particular committee; but, had it not been so, the committee would certainly have had to point out that, although the alterations to the engine to suit it to alcohol as fuel are not considerable, the use of benzol enables the engine to be used without any alterations whatever.

The main difficulty seen by the committee is the question of supply. "It appears unlikely that any considerable quantity of alcohol can be manufactured in Australia from either waste or raw materials not at present utilised." The same remark applied to benzol before the war, but will it apply after? The quantity of benzol at present being produced for munitions is shrouded by the secrecy of war, but it is not out of place to speculate that when the need for vast munitions ceases a supply of benzol may be released for use in internal-combustion motors which will give a new aspect to the problem which this Australian committee is considering. The further reports of the committee will be looked forward to with interest.

\section{NOTES.}

Among the several matters which the deputation from the Joint Committee of Approved Societies and the Conference of the Amalgamated Society of Industrial Assurance brought before the Prime Minister, when he received it on October II, not the least important was that with regard to the early establishment of a Ministry of Health. Mr. Lloyd George did not fail to recognise its mportance, and in the reply which he made to the deputation showed that he was alive to the necessities of the case and understood the point of view of the deputation. In effect, the demand made was that, in connection with the establishment of the Ministrv, the aim should be to give satisfaction to the national insurance organisations. It was suggested, too, that the one thing that must be done was to avoid allowing the Local Government Board to have any part in the work. The reason for asking this 